\title{
Comparison of the Effects of Two Topical Fluoride Regimens on Demineralized Enamel in vivo
}

\author{
J.W. CLARK, R.E. CORPRON, F.G. MORE, J.W. EASTON, D.F. MERRILL, and C.J. KOWALSKI ${ }^{\sharp}$ \\ Department of Pediatric Dentistry, Biostatistics Unit, Dental Research Institute, School of Dentistry, University of Michigan, \\ Ann Arbor, Michigan 48109
}

\begin{abstract}
The purpose of this investigation was to study the intra-oral remineralization of acid-softened enamel by a NaF dentifrice compared with that from a combination of topical $F$ agents. Bovine enamel slabs were demineralized with $0.1 \mathrm{~mol} / \mathrm{L}$ lactic acid at $\mathrm{pH} 4.0$ for $14 \mathrm{hr}$ and then mounted in a removable mandibular appliance. Control slabs were worn for $96 \mathrm{hr}$ by seven adult males who brushed daily with a $F$-free dentifrice. Test slabs were brushed with a NaF dentifice $4 \times 1$ day or with the same dentifrice $4 \times 1$ day and a $0.02 \%$ APF mouthrinse and a $0.4 \% \mathrm{SnF}_{2}$ gel which were applied oncelday for three days. The natural dentition was also brushed with the NaF dentifrice during both test periods. Microhardness testing was performed on sound enamel, and after acid-softening, intra-oral exposure (IOE), and acid resistance testing (ART) in $0.01 \mathrm{~mol} / \mathrm{L}$ lactic acid at $\mathrm{pH} 4.0$ for 24 $\mathrm{hr}$. Control and test slabs were etched with $0.5 \mathrm{~mol} / \mathrm{L} \mathrm{HClO} \mathrm{O}_{4}$ for from 15 to $60 \mathrm{sec}$. The $F$ content was measured with a $F$ electrode and $\mathrm{PO}_{4}$ by spectrophotometry. Contact microradiography and image analyses were performed on control and test slabs so that changes in mineral content resulting from treatment could be assessed. Both test groups were significantly harder after both IOE and ART than were controls, but no differences appeared between the effects of the two test groups. The F content of control slabs was significantly less than that of both test groups, and the combination-treated slabs showed greater $F$ than did the dentifrice-treated slabs. Microradiographs revealed a higher mineral content in the basal $2 / 3$ of combinationtreated lesions, while diffuse mineral deposition occurred, especially subjacent to the surface in the dentifrice-treated lesions. Control lesions showed little added mineral.
\end{abstract}

\section{J Dent Res 67(6):954-958, June, 1988}

\section{Introduction.}

Following recognition of the anticaries benefits derived from prolonged ingestion of optimally fluoridated drinking water (Dean et al., 1942; Ast et al., 1956; Blaney and Hill, 1967), extensive research has resulted in the development of a variety of topical fluorides, including professionally applied agents, dentifrices, mouthrinses, and a number of other self-applied fluorides (Horowitz, 1973a; Horowitz, 1973b). Such topical fluoride agents were demonstrated to be effective in the prevention of dental caries in both fluoridated and non-fluoridated areas (Anderson et al., 1982; O'Mullane, 1982; Kalsbeek, 1982; Koch, 1982). Subsequently, it was postulated that the reduction in caries following the application of topical $F$ agents was due, in part, to remineralization of existing incipient caries lesions (Koulourides et al., 1974; Grøn, 1977; Mellberg and Ripa, 1983).

Attempts to determine the most effective method(s) of remineralization of incipient enamel caries have led investigators to postulate that short, repetitive, self-applications of fluorides in relatively low doses such as in dentifrices, mouthrinses, and self-applied gels enhance the remineralizing capacity of saliva (Gelhard et al., 1979; Koulourides and Cameron, 1980; Feath-

Received for publication March 3, 1987

Accepted for publication February 22, 1988

This investigation was supported by USPHS Grant DE-02731 from the National Institute of Dental Research. erstone, 1983). The efficacy of F-containing dentifrices has been reported (Featherstone et al., 1982; Corpron et al., 1986), but little information exists regarding the enhancement of the remineralizing effects of a $F$ dentifrice by the application of additional topical $\mathrm{F}$ agents.

Because of its widespread use, the fluoride-containing dentifrice constitutes an important method for the prevention and/ or remineralization of early dental decay. In this study, the effectiveness of a fluoride-containing dentifrice was used as a treatment standard for comparison with the in vivo effects on demineralized enamel of the application of multiple topical $F$ agents.

\section{Materials and methods.}

The preparation of bovine enamel slabs and their demineralization with $0.1 \mathrm{~mol} / \mathrm{L}$ lactic acid containing $1 \%$ carboxymethyl cellulose with $3.0 \mathrm{mmol} / \mathrm{L}$ calcium and $1.8 \mathrm{mmol} / \mathrm{L}$ phosphate at a $\mathrm{pH}$ of 4.0 has been described previously (Corpron et al., 1986).

Intra-oral procedures. - Removable mandibular acrylic appliances were fabricated for seven male subjects (from 22-55 yrs of age), and sticky wax was used to mount the acid-softened enamel slabs bilaterally in the lingual acrylic of each appliance. The slabs were recessed approximately $1.0 \mathrm{~mm}$ below the surface of the wax to facilitate the accumulation of plaque on the surfaces of the slabs (Corpron et al., 1986).

A total of 96 slabs was required for each subject, 32 for each experimental regimen and control. Fifteen slabs were designated for microhardness testing, 15 for fluoride biopsy, and two from each regimen for microradiography. Of those demineralized slabs designated for microradiography, half of the surface of each slab was covered with an acid-resistant varnish so that during the intra-oral exposure to the control or one of the experimental regimens, the exposed half of the lesion would demonstrate the effects of the treatment and the covered half would represent the untreated original lesion. Control slabs were worn for separate but equal intervals from treated slabs for both experimental groups. All subjects continued their usual dietary habits, and all lived in a fluoridated area $(1 \mathrm{ppm})$. Each subject wore the appliance continuously except during mealtime. The subjects used a fluoride-free dentifrice (PepsodentLever Brothers, NY) four times daily during the four-day control period.

\section{Experiment I-NaF Dentifrice}

The subjects first brushed their teeth for $60 \mathrm{sec}$ with a $0.24 \%$ $\mathrm{NaF}$ dentifrice (Crest with Fluoristat - Procter \& Gamble, Cincinnati, $\mathrm{OH}$ ) and then gently brushed the 32 enamel slabs with the same dentifrice for $60 \mathrm{sec}$. The dentifrice was applied (after removal of the appliance from the mouth) by use of a fresh supply of toothpaste but without the saliva being rinsed from the surfaces of the slabs. The appliance was immediately replaced in the mouth after being gently rinsed with tap water. Each subject brushed $4 \times$ daily (i.e., after each regular meal 
and before bedtime) for three days. Each subject wore the appliance for an additional $24 \mathrm{hr}$, gently cleansing the appliance and slabs with a soft brush.

\section{Experiment II-Combination}

The subjects removed their appliances to brush their teeth for $60 \mathrm{sec}$ with $0.24 \% \mathrm{NaF}$ dentifrice (Crest with Fluoristat, Procter \& Gamble, Cincinnati, $\mathrm{OH}$ ) and then gently brushed the enamel slabs $4 \times$ daily with a fresh supply of the same dentifrice for $60 \mathrm{sec}$, replacing the appliance in the mouth after rinsing with tap water. In addition, the subjects rinsed, while wearing the appliance, with $5 \mathrm{~mL}$ of a $0.02 \%$ APF mouthrinse (Phos-Fluor, Hoyt Laboratories, Needham, MA) for $60 \mathrm{sec}$ once/day following the noontime brushing. Subjects were instructed not to rinse or eat for $30 \mathrm{~min}$ following the mouthrinse procedure. Finally, the subjects applied approximately $0.8 \mathrm{~g}$ of $0.4 \%$ stannous fluoride gel (GEL-KAM, Scherer Laboratories, Inc., Dallas, TX) once/day immediately following the bedtime brushing. The appliance was removed from the mouth for performance of the one-minute gel application with a cotton-tip applicator. This application followed the bedtime brushing, which presumably removed much of the plaque accumulation on the surfaces of the slabs. The appliance was then replaced in the mouth unrinsed, which allowed the gel to mix with the subjects' saliva. Following the final gel application on the 3rd day, the appliance was worn for an additional $24 \mathrm{hr}$ without further exposure to any fluoride treatment. During the fourth day, subjects gently cleansed the natural dentition with the same fluoride-free dentifrice used for the control period. The test enamel slabs were cleaned with cotton swabs and distilled water.

Microhardness evaluation. - Microhardness testing was performed at four stages: (a) abraded, sound enamel, (b) after acid-softening, (c) after intra-oral exposure (IOE), and (d) after acid-resistance testing (ART). Details of surface microhardness testing and acid-resistance testing have been previously reported by Corpron et al. (1986). The method described by Gelhard et al. (1979) was modified to calculate percentage changes in indenter depth following both IOE and ART. The percent changes of the 15 slabs for each person were averaged for IOE and ART to obtain a single representative value for each person at these times.

Fluoride analysis. - After IOE, the 15 slabs worn by each subject for control and both test groups were immersed in 1.0 $\mathrm{mol} / \mathrm{L} \mathrm{KOH}$ for $24 \mathrm{hr}$ at room temperature to remove the alkalisoluble fluoride from the surface (Caslavska et al., 1975). The analysis for alkali-soluble $F$ was performed by the method of de Bruyn et al. (1985). Subsequently, the slabs were rinsed thoroughly with double-distilled water, and five successive enamel layers were removed for each slab by immersion in $0.5 \mathrm{~mol} / \mathrm{L}$ perchloric acid for $15,30,30,60$, and $60 \mathrm{sec}$, by means of the method previously described by Corpron et al. (1986). Phosphate concentration was determined by the method of Gee et al. (1954). The fluoride content of each etch was reported in $\mathrm{ng}$ and the weight of $\mathrm{PO}_{4}$ in $\mu \mathrm{g}$. The values of the 15 slabs for each person were averaged to obtain a single representative value for each person at each etch.

Microradiography. - After intra-oral exposure, control and test slabs were embedded in epoxy resin (Epon 812, Ernest Fullam, Inc., Schenectady, NY), cured overnight at $37^{\circ} \mathrm{C}$, and sectioned with a diamond wheel saw to obtain 3-5 sections per slab. The sections, which originally measured from 250 to 280 $\mu \mathrm{m}$ in thickness, were individually hand-polished on 600 -mesh abrasive paper to a thickness of $100 \pm 5 \mu \mathrm{m}$.

Contact microradiographs were made directly of the sections, by means of high-resolution plates (Eastman Spectroscopic Plates, Type 649). The x-ray generator (Faxitron 43804N,
Hewlett Packard, McMinnville, OR) was operated at a standard setting of $20 \mathrm{kV}$ and $2.8 \mathrm{~mA}$ for $60 \mathrm{~min}$ at a source distance of $65 \mathrm{~cm}$.

Control, dentifrice-treated, and combination-treated sections of each subject were placed on the same high-resolution plates to ensure uniform exposure and contrast.

Radiographs were evaluated by means of a Leitz Diaplan microscope equipped with a variolume to guarantee even illumination of the field and equipped with a Newvicon television camera to obtain the images of each section. An algorithm was applied to correct for any non-linearity of the camera. The video images were digitized by an International Imaging Systems Model 75 image processor $\left(I^{2} S\right.$, San Jose, CA), linked to a Mass-Comp MC-5600 computer (Westford, MA). Digital images were made of each section, with the same light intensity and gain settings used to assure standardization of images. Grey values ranging from black $(0)$ to white (255) were read and recorded. The corrected images were read in grey values and, by means of standards, converted to optical density units.

An aluminum stepwedge $(18 \mu \mathrm{m} / \mathrm{step})$ was analyzed as a standard to determine optical density (OD) in a range that was within the range of the OD of the experimental samples. The OD of each step of the stepwedge was determined. By means of known densitometric standards, grey values were assigned correct densitometric values.

The polychromatic nature of the x-ray beam generated by the tungsten anode used in this study precluded the use of the method of Angmar et al. (1963), which requires a monochromatic X-ray beam in order to calculate the percent mineral by volume. The method used in this study was a modification of that described by Mallon and Mellberg (1985), whereby the mineral density of control and treated lesions was reported as percent of sound enamel. The data were evaluated by regression analysis and the results reported as percent sound enamel.

Statistical methods. - Since, in this experiment, each subject received each of the control and two treatment regimens, a procedure reflecting the repeated measures structure of the design is appropriate. Accordingly, the mean values of the percent changes in indenter penetration for the control, dentifricetreated, and combination-treated specimens were compared by a repeated-measures analysis of variance (Winer, 1962) with two "within" factors (treatment and time-of-measurement, viz., IOE and ART). Multiple comparisons were accomplished by Scheffe's procedure. The relationships between $\mathrm{F}$ uptake (ng) and $\mathrm{PO}_{4}$ content $(\mu \mathrm{g})$ for controls and each set of test slabs were analyzed similarly by use of representative values of $\mathrm{PO}_{4}$ content (i.e., here, the two "within" factors were treatment and specified values of $\mathrm{PO}_{4}$ content). Again, Scheffe's method of multiple comparisons was used to compare each pair of means when the overall analysis of variance proved significant.

\section{Results.}

Microhardness testing. - Values for $\bar{\chi}$ and SD of the percentage changes in indenter penetration for control, dentifricetreated, and combination-treated specimens following IOE and ART are shown in the Table, along with the results of Scheffe's method of multiple comparisons.

Both treatment groups demonstrated significantly greater percentage recovery for both IOE and ART as compared with controls, while no differences appeared between the two treatment groups. Large individual subject variations were observed for all groups, while no constant site-to-site variation in IOE and ART values was observed for individual subjects.

Fluoride uptake. - The fluoride contents for control, combination-treated, and dentifrice-treated slabs are shown in Fig. 1. The three curves demonstrate the ratio of fluoride (ng) to 
TABLE

CHANGE IN INDENTER PENETRATION (\% RECOVERY) MEAN $( \pm S D)$ VALUES

\begin{tabular}{llc}
\hline \hline$(\mathrm{N}=7)$ & \multicolumn{1}{c}{ IOE } & \multicolumn{1}{c}{ ART } \\
\hline Control & $35.6 \pm 7.7$ & $1.4 \pm 3.8$ \\
Dentifrice & $71.1^{*} \pm 11.9$ & $44.9^{*} \pm 14.8$ \\
Combination & $68.0^{*} \pm 16.6$ & $46.3^{*} \pm 12.9$ \\
\hline
\end{tabular}

${ }^{*}$ Significant difference from controls $(p<0.05)$.

No significant difference.

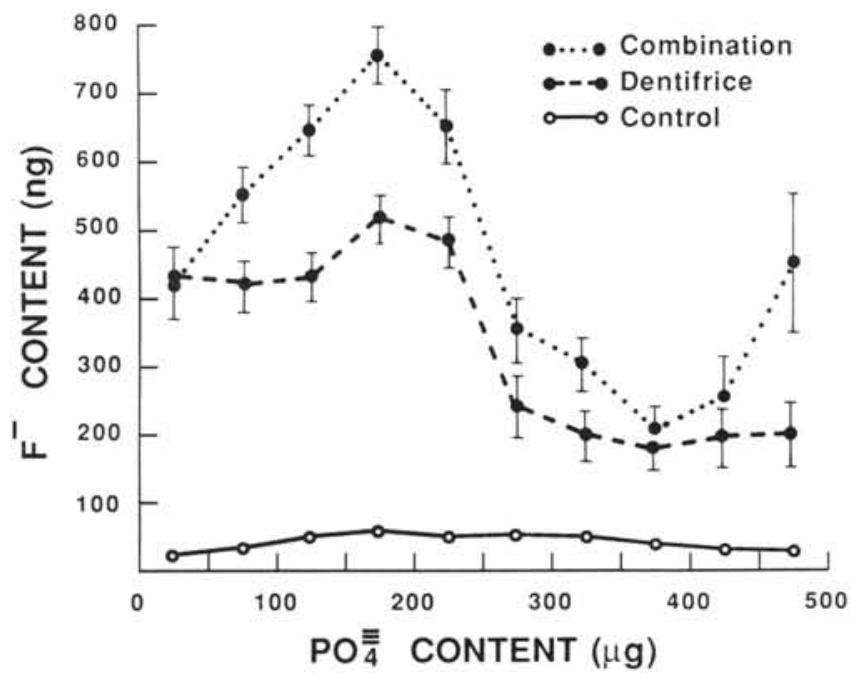

Fig. 1-Fluoride-to-phosphate ratio for control, dentifrice-treated, and combination-treated enamel slabs.

the phosphate $(\mu \mathrm{g})$ content for the controls and experimental slabs. Although the precise depth of each etch is unknown, the area between each curve represents the difference in the total fluoride content among the three groups.

The experimental regimens resulted in significantly greater fluoride deposition throughout the depths of the lesions when compared with the controls $(\mathrm{p}<0.05)$. Additionally, the combination-treated slabs demonstrated significantly greater fluoride content than the dentifrice-treated slabs $(\mathrm{p}<0.05)$ (Fig. 1). There was no significant site-to-site variation in the fluoride content of individual slabs for either test regimen.

There were no significant differences in the mean values for alkali-soluble $\mathrm{F}$ content of the $\mathrm{KOH}$ washes for control, dentifrice-treated, and combination-treated slabs.

Microradiography. - The depths of the artificial lesions measured on the microradiographs were generally regular for all lesions $(60 \pm 10 \mu \mathrm{m})$. The control lesions demonstrated only minor mineral deposition in the base of the lesion compared with the original lesions unexposed to saliva (Figs. 2 \& 5). The dentifrice-treated lesions demonstrated a generalized diffuse increase in mineral throughout the lesion, with increased deposition subjacent to the surface of the specimen (Figs. 3 \& 5). The combination-treated lesions exhibited increased mineral deposition in the basal two-thirds of the lesions (Figs. 4 \& 5).

\section{Discussion.}

The in vivo remineralizing actions of individual topical agents have been widely investigated, but the actions of combinations of agents have not been widely studied. The effects of fluoridecontaining dentifrices are well-documented (Arends and Gel-

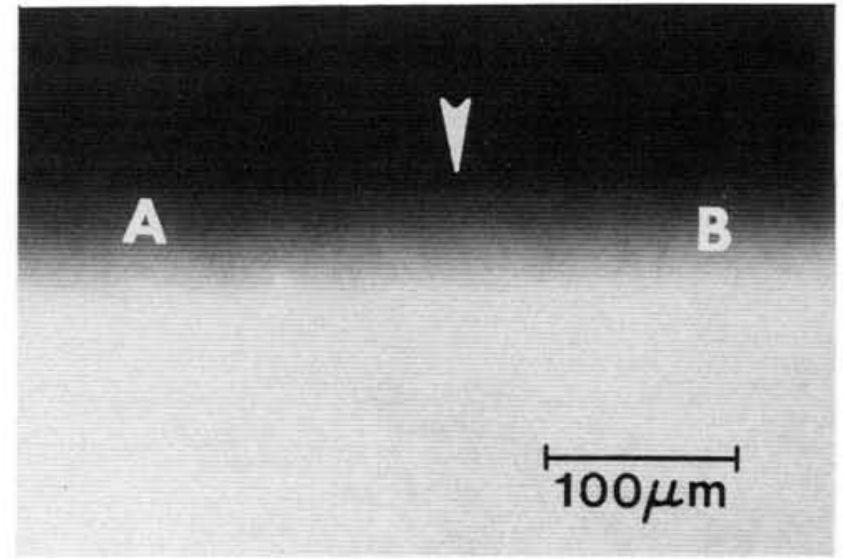

Fig. 2-Microradiograph of control lesion. $A=$ Untreated area of lesion. $\mathrm{B}=$ Control or treated area of lesion. Arrow $=$ Junction of unexposed and treated lesions.

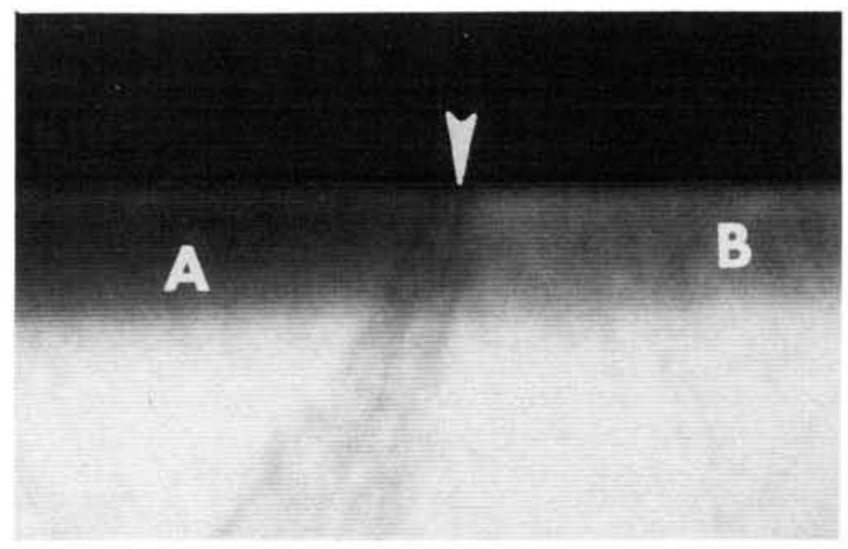

Fig. 3-Microradiograph of dentifrice-treated lesions. $A=$ Untreated area of lesion. $\mathrm{B}=$ Control or treated area of lesion. Arrow $=$ Junction of unexposed and treated lesions.

hard, 1983; Featherstone, 1983; Mellberg and Chomicki, 1983; Corpron et al., 1986), and fluoride mouthrinses have also demonstrated significant remineralizing capacity of enamel lesions in vivo (Featherstone et al., 1982; Corpron et al., 1986). The early $\mathrm{SnF}_{2}$ agents (i.e., $8 \% \mathrm{SnF}_{2}$ solutions) were effective in reducing enamel solubility (Muhler and van Huysen, 1947; Feller, 1974) and inhibiting bacterial growth (Tinanoff and Weeks, 1979), but such agents experienced disuse because of an unpleasant taste and frequent gastric distress following application. The current self-applied $0.4 \% \mathrm{SnF}_{2}$ gels $(1000 \mathrm{ppm}$ F) represent a significant reduction in the $\mathrm{F}$ content $(20$-fold reduction compared with the $8 \%$ solution), offer an acceptable taste, and have demonstrated a limited capacity to remineralize enamel lesions (Clark et al., 1986).

The remineralization of early caries lesions has increasingly been recognized as an important mechanism whereby $\mathrm{F}$ reduces caries incidence (Featherstone, 1983; Thylstrup et al., 1983). While dentists continue to recommend topical $\mathrm{F}$ agents such as mouthrinses and self-applied gels to supplement the effects of the F dentifrice for caries-prone patients, there still exists meager evidence to justify the added cost or to support the additional effects of the use of multiple $\mathrm{F}$ agents for the remineralization of early caries. Möller and Schröder (1986) reported a significant decrease in the size of natural "white 


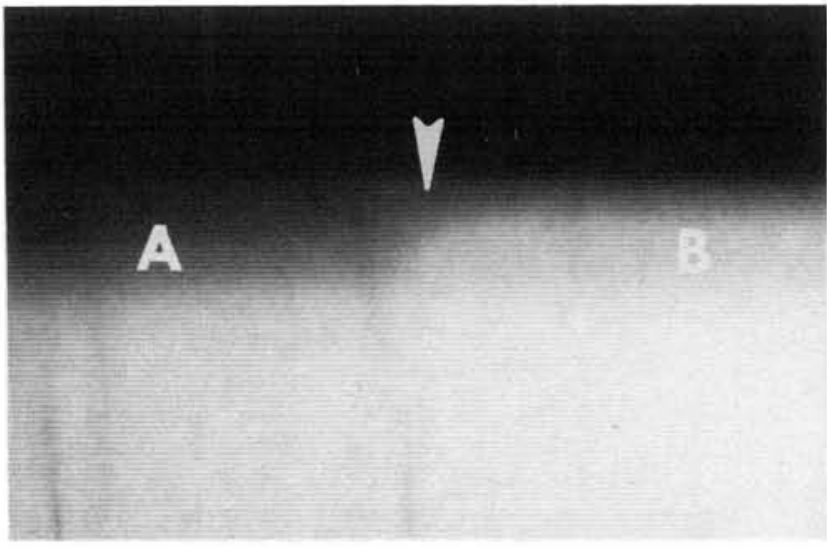

Fig. 4-Microradiograph of combination-treated lesion. $\mathrm{A}=$ Untreated area of lesion. B = Control or treated area of lesion. Arrow = Junction of unexposed and treated lesions.

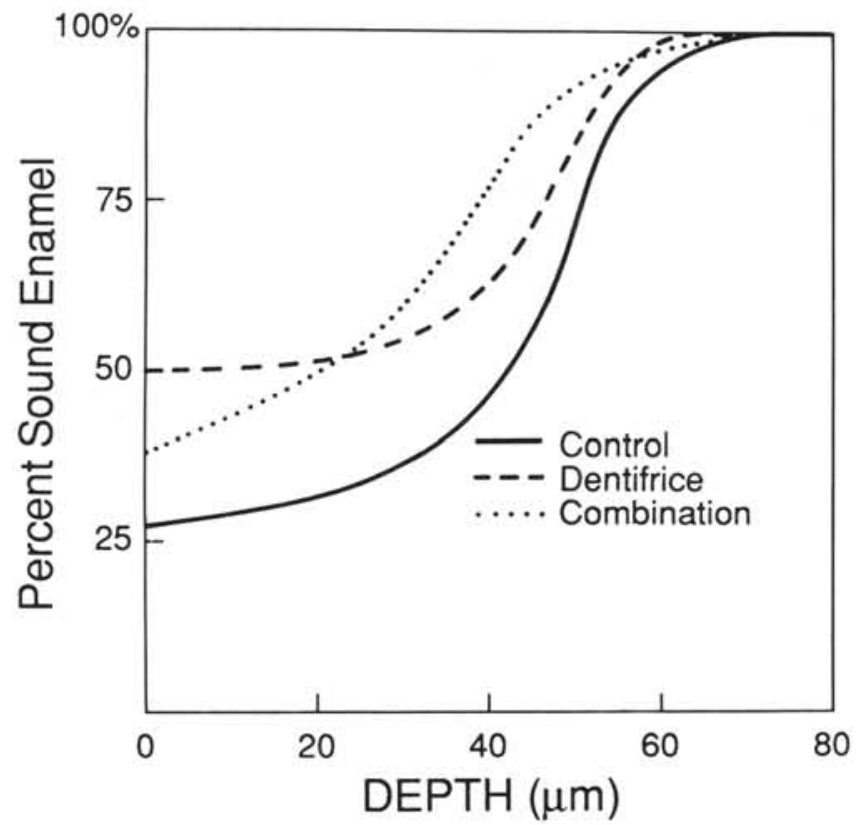

Fig. 5-Quantitative microradiography. The percent of sound enamel $v s$. the depth is graphically illustrated for control, dentifrice-treated, and combination-treated enamel slabs.

spot" lesions in vivo following the daily application of a Fcontaining dentifrice and a F mouthrinse and the application of a F-containing varnish every ten days. However, the effect of this combination was not compared with that of the dentifrice alone, leaving unresolved the question of whether multiple agents actually provided additional efficacy in the remineralization of enamel lesions over the use of the dentifrice alone.

The $\mathrm{KOH}$ wash prior to fluoride uptake analysis of respective lesions was used to remove alkali-soluble $\mathrm{F}$ which may have accumulated on the enamel surface (Caslavska et al., 1975). The results showed minimal alkali-soluble $\mathrm{F}$ on the surfaces of the specimens for controls and both treatment regimens, which if present and unremoved would have affected the results of the $\mathrm{F}$ analysis of at least the outer layer.

The effects of $\mathrm{F}$ upon remineralization have traditionally been evaluated by microhardness testing, $\mathrm{F}$ uptake, and mi- croradiography. In this study, microhardness testing revealed that although both treatment groups demonstrated significantly greater rehardening and resistance to acid attack than controls, no differences appeared between treatment groups. White (1987) reported that the linear relation between surface hardness and lesion mineral content is restricted to early lesions of shallow depths $(<50 \mu \mathrm{m})$, whereas the lesions used in this study approached $60 \pm 10 \mu \mathrm{m}$ in depth, and the microhardness testing revealed only gross differences (Table). When considered alone, the microhardness data suggested no difference between the dentifrice-treated and the combination-treated groups, whereas the $\mathrm{F}$ uptake and quantitative microradiographic evidence both demonstrated distinct differences between the treatments (Figs. $1-5)$.

The pattern of the mineral deposition recorded microradiographically (Figs. 2-4, 5) did not closely parallel the $\mathrm{F}$ uptake profiles of the respective lesions (Fig. 1). Although the F content of the combination-treated lesions exceeded that of the dentifrice-treated lesions throughout the depths of the lesions, the most substantial mineral deposition occurred basally in the combination-treated lesions, where the differences in $\mathrm{F}$ content between the two treatment groups were minimal. Conversely, the greatest differences in F content occurred subjacent to the surface (Fig. 1), where the mineral content of the dentifricetreated lesions exceeded that of the combination-treated lesions (Figs. 3-5). The increased mineral density of the combinationtreated lesions may have been caused, at least in part, by the masking effect of the tin deposited from the $\mathrm{SnF}_{2}$ gel (Lobene et al., 1967); however, Arends et al. (1984) have suggested a logical explanation for the protective effects of $\mathrm{F}$ upon enamel. The non-specific adsorption of $F$, which occurs in the enamel prior to the formation of fluoridated apatite (FAP), is preferentially concentrated in the Stern layer. This layer is rich in $\mathrm{Ca}^{2+}$ and also $\mathrm{F}^{-}$following fluoride application, suggesting that apatitic surfaces act as $\mathrm{CaF}_{2}$ nucleators. Unlike the chemically stable FAP formed by the specific adsorption involving the exchange of $\mathrm{OH}^{-}$with $\mathrm{F}^{-}$along the enamel crystallites, the non-specifically-adsorbed $\mathrm{F}$ does not appear microradiographically as increased mineral density, as occurs with the newly formed FAP (Figs. 3 \& 4).

The surface-softened lesion served as an appropriate test of the remineralizing capacity for the short-term, intensive combination regimen in this in vivo study. Arends and Gelhard (1983) reported that the in vivo remineralization of subsurface lesions progressed slowly, whereas surface-softened lesions, which correspond to the earliest natural lesions, remineralize relatively fast and more completely than the subsurface lesions. The intra-oral model used in this study had previously been utilized to establish the short-term remineralization of surfacesoftened lesions by a NaF dentifrice (Corpron et al., 1986), and concern for long-term compliance of the combination regimen prompted the use of the same time span for the combination, thereby establishing the relative efficacy of the two different regimens.

The combination regimen, though an unlikely program for children because of the potential for significant ingestion of $\mathrm{F}$ from the topical agents, could be applied to caries-prone adults where applications of multiple $\mathrm{F}$ agents for relatively short periods could exert substantial effect upon early caries lesions. The combinations of the mouthrinse and the $\mathrm{SnF}_{2}$ gel were not individually determined in this study, but the combination of the two agents was utilized in an attempt to demonstrate a significantly greater effect than the $\mathrm{F}$ dentifrice alone. None of the subjects found difficulty in compliance with the shortterm regimen, and further studies involving individual agents (i.e., mouthrinse and self-applied gels) used with a F dentifrice for longer durations should be pursued. 


\section{REFERENCES}

ANDERSON, R.J.; BRADNOCK, G.; BEAL, J.F.; and JAMES, P.M.C. (1982): The Reduction of Dental Caries Prevalence in English School Children, J Dent Res 61:1311-1316.

ÅNGMAR, B.; CARLSTRÖM, D.; and GLAS, J.E. (1963): Studies on the Ultrastructure of Dental Enamel. IV. The Mineralization of Normal Human Enamel, $J$ Ultrastruct Res 8:12-23.

ARENDS, J. and GELHARD, T. (1983): In vivo Remineralization of Human Enamel. In: Demineralization and Remineralization of the Teeth, S.A. Leach and W.M. Edgar, Eds., Oxford: IRL Press Ltd., pp. 1-16.

ARENDS, J.; NELSON, D.G.A.; DIJKMAN, A.G.; and JONGEBLOED, W.L. (1984): Effects of Various Fluorides on Enamel Structure and Chemistry. In: Cariology Today, Basel: Karger, pp. 245-258.

AST, D.; SMITH, D.; WACHS, B.; and CANTWELL, K. (1956): Newburgh-Kingston Caries-Fluorine Study XIV: Combined Clinical and Roentgenographic Dental Findings after Ten Years of Fluoride Experience, $J$ Am Dent Assoc 52:314-325.

BLANEY, J.R. and HILL, I.N. (1967): Fluoride and Dental Caries, $J$ Am Dent Assoc 74:233-302.

CASLAVSKA, V.; MORENO, E.C.; and BRUDEVOLD, F. (1975): Determination of Calcium Fluoride from in vitro Exposure of $\mathrm{Hu}$ man Enamel to Fluoride Solutions, Arch Oral Biol 20:333-339.

CLARK, J.W.; QUIROS, A.; CORPRON, R.E.; MORE, F.G.; and KOWALSKI, C.J. (1986): In vivo Effects of $\mathrm{SnF}_{2}$ Gel on Acidsoftened Enamel, J Dent Res 65:698-702.

CORPRON, R.E.; MORE, F.G.; CLARK, J.W.; KORYTNICKI, D.; and KOWALSKI, C.J. (1986): In vivo Remineralization of Artificial Enamel Lesions by a Fluoride Dentifrice or Mouthrinse, Caries Res 20:48-55.

DEAN, H.T.; ARNOLD, F.A., Jr.; and ELVOVE, E. (1942): Domestic Water and Dental Caries. V. Additional Studies of the Relation of Fluoride Domestic Waters to Dental Caries Experience in 4225 White Children, Aged 12 to 14 Years, of 13 Cities in 4 States, Pub Health Reports 57:1155-1179.

de BRUYN, H.; HUMMEL, H.; and ARENDS, J. (1985): In vivo Effects of a Fluoridated Varnish with Various Fluoride Contents on Human Enamel, Caries Res 19:407-413.

FEATHERSTONE, J.D.B. (1983): Remineralization of Artificial Caries Lesions in vivo and in vitro. In: Demineralization and Remineralization of the Teeth, S.A. Leach and W.M. Edgar, Eds., Oxford: IRL Press Ltd., pp. 89-110.

FEATHERSTONE, J.D.B.; CUTRESS, T.W.; RODGERS, B.E.; and DENNISON, P.J. (1982): Remineralization of Artificial Carieslike Lesions in vivo by a Self-administered Mouthrinse or Paste, Caries Res 16:235-242.

FELLER, R.P. (1974): Reduction of Solubility by Daily Use of a $0.4 \% \mathrm{SnF}_{2} \mathrm{Gel}, J$ Dent Res 53:1280-1283.

GEE, A.; DOMINGUES, L.; and DIETZ, V. (1954): Determination of Inorganic Constituents in Sucrose Solutions, Anal Chem 26:14871491.

GELHARD, T.; TEN CATE, J.; and ARENDS, J. (1979): Rehardening of Artificial Enamel Lesions in vivo, Caries Res 13:80 83.
GRØN, P. (1977): Can Incipient Lesions Be Arrested? In: Proceedings of Symposium on Incipient Caries of Enamel, $N$. Rowe, Ed., Ann Arbor: The University of Michigan, pp. 145-165.

HOROWITZ, H.S. (1973a): Fluoride: Research on Clinical and Public Health Application, $J$ Am Dent Assoc 87:1013-1018.

HOROWITZ, H.S. (1973b): A Review of Systemic and Topical Fluorides for the Prevention of Dental Caries, Community Dent Oral Epidemiol 1:104-114.

KALSBEEK, H. (1982): Evidence of Decreased Prevalence of Dental Caries in The Netherlands: An Evaluation of Epidemiological Caries Surveys of 4-6- and 11-15-year-old Children, Performed between 1965 and 1980, $J$ Dent Res 61:1321-1326.

KOCH, G. (1982): Evidence for Declining Caries Prevalence in Sweden, $J$ Dent Res 61:1340-1345.

KOULOURIDES, T. and CAMERON, B. (1980): Enamel Remineralization as a Factor in the Pathogenesis of Dental Caries, $J$ Oral Pathol 9:255-269.

KOULOURIDES, T.; PHANTUMVANIT, P.; MUNKSGAARD, E.C.; and HOUSCH, T. (1974): An Intraoral Model Used for Studies of Fluoride Incorporation in Enamel, $J$ Oral Pathol 3:185196.

LOBENE, R.R.; ZULGER-NAIN, B.J.; and HEIN, J.W. (1967): Masking of Enamel Caries by Topically Applied Stannous Fluoride: A Source of Error in Clinical Diagnosis, $J$ Oral Ther Pharmacol 3:35-43.

MALLON, D.E. and MELLBERG, J.R. (1985): Analysis of Dental Hard Tissue by Computerized Microdensitometry, $J$ Dent Res 64:112-116.

MELLBERG, J. and CHOMICKI, W. (1983): Fluoride Uptake by Artificial Caries Lesions from Fluoride Dentifrices in vivo, $J$ Dent Res 62:540-542.

MELLBERG, J. and RIPA, L. (1983): Fluoride in Preventive Dentistry. Chicago: Quintessence Pub. Co., pp. 41-80.

MÖLLER, H. and SCHRÖDER, V. (1986): Early Natural Subsurface Caries. A SEM Study of the Enamel Surface before and after Remineralization, Caries Res 20:97-102.

MUHLER, J.C. and VAN HUYSEN, G. (1947): Solubility of Enamel Protected by Sodium Fluoride and other Compounds, $I$ Dent Res 26:119-127.

O'MULLANE, D.M. (1982): The Changing Pattern of Dental Caries in Irish Schoolchildren between 1961 and 1981, J Dent Res 61:13171320.

THYLSTRUP, A.; FEATHERSTONE, J.D.B.; and FREDEB $\varnothing, \mathrm{L}$. (1983): Surface Morphology and Dynamics of Early Enamel Caries Development. In: Demineralization and Remineralization of the Teeth. S.A. Leach and W.M. Edgar, Eds., Oxford: IRL Press, pp. 165-184.

TINANOFF, N. and WEEKS, D.B. (1979): Current Status of SnF as an Antiplaque Agent, Pediat Dent 1:199-204.

WHITE, D.J. (1987): Reactivity of Fluoride Dentifrices with Artificial Caries. I. Effects of Early Lesions: F Uptake, Surface Hardening, and Remineralization, Caries Res 21:126-140.

WINER, B.J. (1962): Statistical Principles in Experimental Design. New York: McGraw-Hill. 